\title{
On the Evolution of Virtualization and Cloud Computing: A Review
}

\author{
Awodele Oludele, Emmanuel C. Ogu", Kuyoro 'Shade, Umezuruike Chinecherem \\ Department of Computer Science and Information Technology, School of Computing and Engineering Sciences, Babcock University, \\ Ilisan-Remo, Ogun State. Nigeria \\ *Corresponding author: ecoxd1@yahoo.com
}

Received November 27, 2014; Revised December 20, 2014; Accepted December 25, 2014

\begin{abstract}
Cloud computing, the technology that makes it possible for computing resources to be provisioned to clients / subscribers over long distances, as well as its component technology - virtualization, which makes it possible for multiple guest systems to co-reside on a single host machine and share the computing resources of the host, have both become very popular technologies that have witnessed giant improvements in the $21^{\text {st }}$ century. This is a review paper that presents an overview of the technologies of virtualization and cloud computing, tracing their history and evolution down a timeline to what they have today, and providing pointers to prospects of future advancements to virtualization and cloud computing.
\end{abstract}

Keywords: virtualization, cloud computing, computing resources, clients / subscribers

Cite This Article: Awodele Oludele, Emmanuel C. Ogu, Kuyoro 'Shade, and Umezuruike Chinecherem, "On the Evolution of Virtualization and Cloud Computing: A Review." Journal of Computer Sciences and Applications, vol. 2, no. 3 (2014): 40-43. doi: 10.12691/jcsa-2-3-1.

\section{Introduction}

With the successful delivery of the first message over the Advanced Research Projects Agency Network (ARPANet) at the peak of the American Cold War, it was instilled in the minds of the over 1000 witnesses present that a technological revolution was soon to be born. The possibility of remote access to files was confirmed. On January 1, 1983, with the successful establishment of the first TCP/IP communication, the internet was birthed [1].

The advent of the Internet was welcomed and found its first use in research and academics. But as the internet grew over the years, it gradually crawled out of the domain of research and academics to playing vital roles in healthcare and in the workings of various governments and economies [2,3], and this helped to further convince cynics that this new technology had come to stay.

\section{Technological Evolution}

The birth of the internet was however, foretold about two decades earlier when John McCarthy, speaking at the MIT Centennial in 1961 was quoted as saying, "If computers of the kind I have advocated become the computers of the future, then computing may someday be organized as a public utility just as the telephone system is a public utility... The computer utility could become the basis of a new and important industry. [4]" Little did he know that it wasn't going to be very long before this dream of his came to reality.
By the 1970s, mainframe users saw the first implementation of virtualization and symmetric multiprocessing, where different users could use the resources of a single machine to execute different processes concurrently. But as the Internet continued to expand, organizations, researchers and academicians began to grapple with concerns relating to the high cost of computers at the time and only sparsely intermittent computational needs; they could not justify investing at high costs in a computer that would be idle for most of the time. To assuage theseconcerns, entrepreneurs came up with the idea of "renting" time, making it possible for organizations and users to either own or subscribe to computing resources at much lower costs [5].

It now became possible for users to access large-scale mainframe computer systems from thin clients/terminal machines, often referred to as "static terminals" (see Figure 1) because they were used mainly for communications but had no internal processing capabilities. This idea helped to enhance the efficiency of expensive mainframe systems and reduce idle periodsby allowing multiple users to share both the physical access to the computer from multiple terminals as well as the processing resources (CPU time); thus, allowing for greater returns on investment for companies that practiced such [6]. It is this technology that evolved through various nomenclatures - such as Remote Job Entry in the 1950s [7], Shared and Dedicated Web Hosting (which are forms of Virtual Web Hosting) around 1995 to 1997 [8,9], Virtual Private Server (VPS) Hosting around 1998 [10], Grid/Utility Computing [5,11] - to become Cloud Computing (CC) about three decades later.

Following the standardization of the Internet and its protocols in the 1990s, around 1995, the company - 
SalesForce began hosting and distributing customer relationship management software over the internet on a subscription basis. The company hosted a platform on their servers that enabled application developers to build applications that could be hosted on these servers. This was one of the pioneer instances of hardware virtualization, which loosely means, "hosting a computer inside another computer", and cloud computing [12].

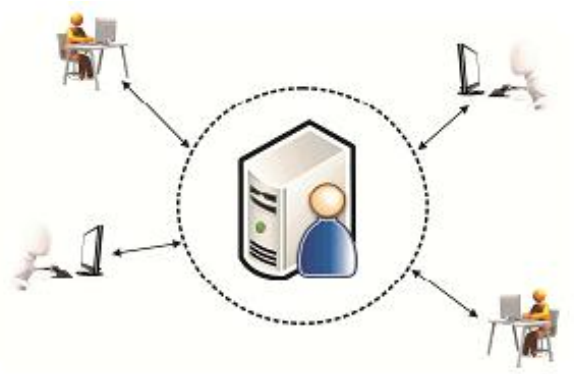

Figure 1. Early years of Cloud Computing [13]

\section{Cloud Computing}

Cloud Computing (CC) is defined by the United States National Institute of Standards and Technology (NIST) as "a model for enabling ubiquitous, convenient, on-demand network access to a shared pool of configurable computing resources (e.g., networks, servers, storage, applications, and services) that can be rapidly provisioned and released with minimal management effort or service provider interaction; having characteristics of on-demand self-service, broad network access, resource pooling, rapid elasticity and payment per usage of various business models. [14]" Cloud computing services are delivered through three standardized service models: the Infrastructure as a Service (IaaS), Platform as a Service (PaaS) and the Software as a Service (SaaS) Models. Figure 2 illustrates the service models of cloud computing, and some popular services that are provided through these models.

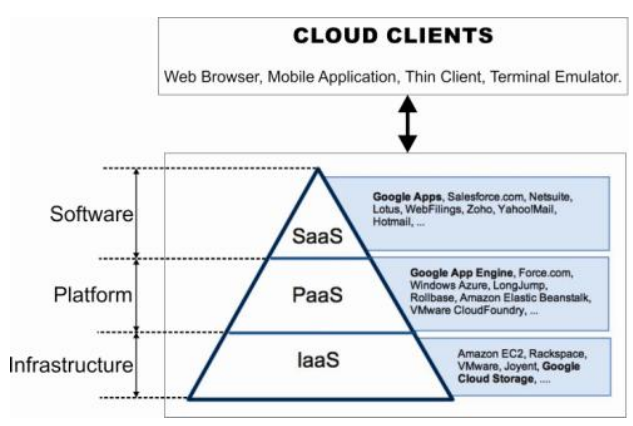

Figure 2. Cloud Computing Service Models[15]

The first / foundational layer of Cloud Computing is the IaaS layer. The products here relate to hardware and associated services such as: general processing, servers, storage devices, database management, and all other hardware related services that are offered as a service to the end user. The next layer is the PaaS layer upon which developers can build and test applications that run on the IaaS, either for the IaaS layer itself or for the SaaS layer above it. The topmost layer is the SaaS, and this deals exclusively with applications for end users [16].
CC service models today are deployed either as Private Clouds (cloud infrastructure provisioned for exclusive use by a single organization comprising multiple consumers), Community Clouds (cloud infrastructure provisioned for exclusive use by a specific community of consumers from organizations that have shared concerns such as: mission, security requirements, policies, and compliance considerations), Public Clouds (cloud infrastructure provisioned for open use by the general public) or Hybrid Clouds (cloud infrastructure comprising two or more distinct cloud infrastructures, whether private, community, or public, that remain unique entities, but are bound together by standardized or proprietary technology enabling data and application portability, such as cloud bursting for load balancing, between clouds). The interactions between these various modes of deployment are illustrated in Figure 3 [16].

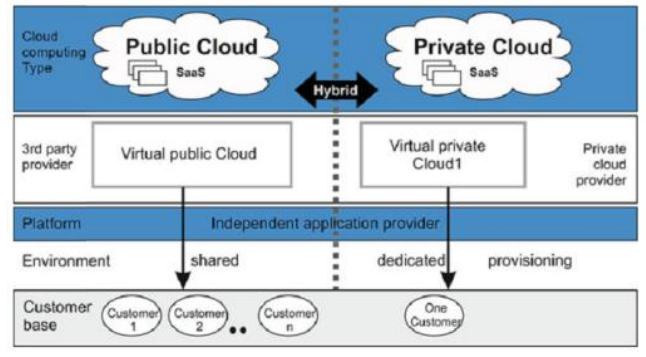

Figure 3. IaaS Deployment Variants[16]

\section{Virtualization}

Virtualization is the technology that allows multiple Virtual Machines (also called guest machines) to run on a single physical machine (also called host machine) and share the resources of the physical machine [17]. This makes it possible for a single physical server to host many guest virtual machines (VMs), operating systems, and applications without the additional cost and complexity that result from running these multiple physical machines individually [18].

Virtualization could occur in various forms. It could be server-based [22], system based [19], storage virtualization [27], desktop virtualization [28] or network virtualization [26]. It could also be hypervisor-based (if a piece of software known as a hypervisor or virtual machine monitor is used to achieve virtualization) or non-hypervisor-based.

Despite variations in organization and architectural implementations, the following core components are generic to virtualization as shown in Figure 4 below:

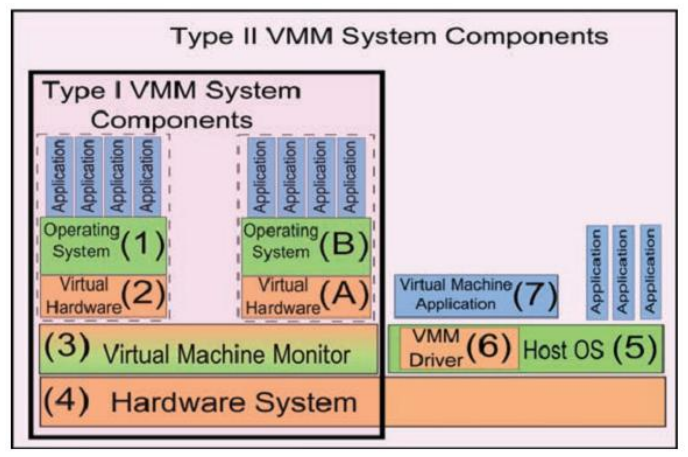

Figure 4. Core Components in Virtualized Architectures (Source: [19]) 
Virtualization is a very fundamental technology that lies at the heart of the operations of modern Cloud Computing Infrastructure [19]. This technology is important to cloud computing because it provides the abstraction that cloud computing enjoys by taking a physical resource such as a server and dividing it into virtual resources called virtual machines (multiple subscribers). In case of server consolidation, many small physical servers are replaced by one larger physical server, to increase the utilization of costly hardware resources such as CPU time [20]. The interactions that take place between the technologies of virtualization and cloud computing are illustrated in Figure 5.

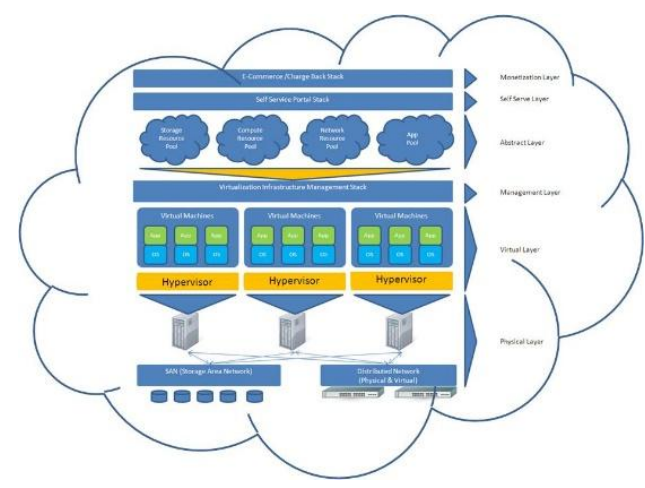

Figure 5. Virtualization and Cloud Computing[21]

The abstraction from the hardware state provided by virtualization allows not only multiple operating systems to coexist on the same hardware, but for one VMM to run on multiple different networked physical systems concurrently [19].

\section{Cloud Computing in the $21^{\text {st }}$ Century}

Two additional factors that have significantly distinguished this new technology from its predecessors and greatly altered its market dynamics in recent years are the speed, dynamism and "far-reach" of the Internet, which makes it possible to transport and deliver computational resources at high speeds, across long distances, and at reduced cost; and the ubiquity of personal computers coupled with the tendency to own computers that satisfy "peak" against "average" need for computational power, directly leaving a good reserve of computational resources idle [5].

Today, Cloud computing is gradually coming to bear in reality as the most formidable path to business and organizational growth and has gained rapid interest and prominence over the past decade. The reason for this rapid growth cannot be far-fetched. Cloud computing simply makes very efficient and flexible, the task of scaling different business services to meet very dynamic business needs; the shared infrastructure and services they provide make it a more prudent venture when compared with other traditional approaches of hosting each of these infrastructure and services locally.

[22], revealed that $90 \%$ of organizations had started implementing Server Virtualization in some form as a part of their IT Infrastructure. This opens the mind to the reality that CC may actually hold the key to formidable business and organizational growth; and the reason for this is simply because $\mathrm{CC}$ enhances the flexibility and efficiency associated with scaling different business services to meet very dynamic business needs [23].

Today, virtualization and cloud computing find its use in business model simulation and testing, computer aided designs of business models, and business process migration, fault tolerance enhancements and backups [13].

\section{Prospects for Virtualization and Cloud Computing}

Some of the prospects which to virtualization and CC have been revealed in researches by [13], [24] and [25] to include: more favourable policy enactments and implementations, ubiquity, centralized storage and accesson-demand, data portability across various cloud platforms, increased consumer-base for private and public clouds, less security concerns and more standardization.

An October 2014 survey carried out by Forrester Consulting on behalf of Infosys revealed by $81 \%$ of companies surveyed that cloud computing is no longer driven by cost savings anymore, but by agility, simplicity and a unified view of IT. This result is expected to increase exponentially within the next few years as more organizations are expected to turn to the cloud for these reasons.

\section{Challenges of Virtualization and Cloud Computing}

Because Virtualization and Cloud Computing are in what seems to be a symbiotic relationship, it would be no gainsaying that challenges faced by one would equally affect the other. The most prevalent challenge of virtualization and cloud computing relate to security. A lot of research has gone into the finding and characterizing these challenges in recent years. One of such researches was by [23]. Figure 6 below summarizes the findings of the research:

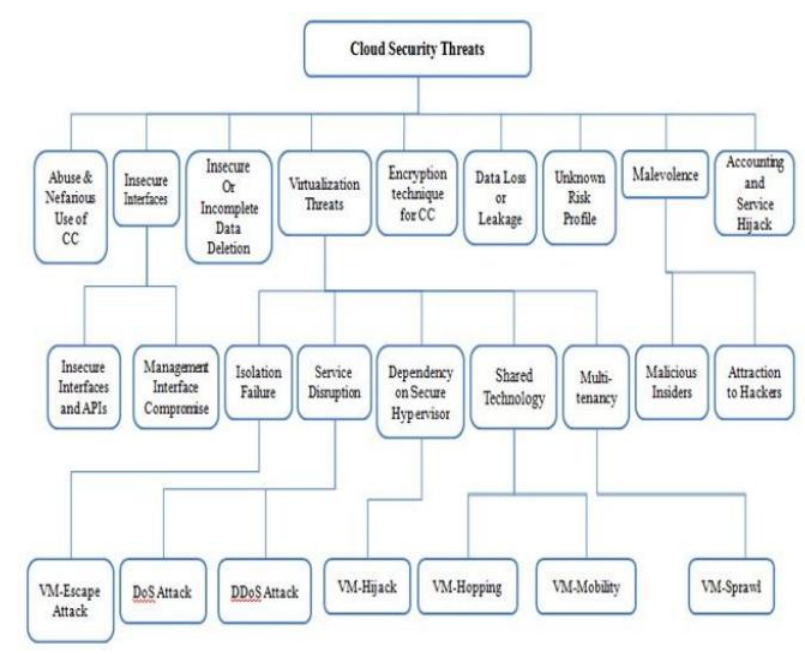

Figure 6. Various categories of Cloud Security threats [23]

\section{Conclusion}

Virtualization and Cloud Computing have come to stay and have carefully carved a niche for themselves in the 
world of business and IT generally. With the many advantages and possibilities provided by these two technologies, and the exciting prospects that have been envisaged, it would be safe to say that these are technologies that would continue to revolutionize and transform many areas of human endeavour for years to come.

\section{References}

[1] Ruthfield, S. (1995, September). The Internet's History and Development From Wartime Tool to the Fish-Cam. Crossroads Special issue on networks, 2(1), pp. 2-4.

[2] Dennis, M. A. (2012, March 2). Denial of Service Attack (DoS Attack). (Encyclopaedia Britannica Online Academic Edition). Encyclopaedia Britannica. Retrieved January 29, 2014, from http://www.britannica.com/EBchecked/topic/1055468/denial-ofservice-attack.

[3] Murphy, D. M. (February 2010). War is War? The utility of cyberspace operations in the contemporary operational environment. Proceedings of the workshop for the center for strategic leadership (pp. 1-4). Pennsylvania, USA.: U.S. Army War College.

[4] Arora, R., \& Bajaj, K. S. (2013, March). Highly Effective Advanced Technology "HEAT" Re-defining Technology for Hospital Management. International Journal of Management \& Behavioural Sciences, Special Edition, 68-73.

[5] Davies, A. (2004, June). Computational intermediation and the evolution of computation as a commodity. Applied Economics, 36(11: 1131).

[6] Christopher, S. (1959). Time Sharing in Large Fast Computers. Proceedings of the International Conference on Information processing, UNESCO.2.19, pp. 336-341. UNESCO. Retrieved February 1, 2014.

[7] IBM. (1970). IBM System/360 Operating System: Conversational Remote Job Entry Concepts and Facilities. International Business Machine (IBM). North Carolina, USA.: IBM Systems Reference Library. Retrieved February 1, 2014, from

http://bitsavers.informatik.uni-stuttgart.de/pdf/ibm/360/rje/GC302012-0_CRJE_Concepts_and_Facilities_Jun70.pdf.

[8] Nikiforakis, N., Joosen, W., \& Johns, M. (2011). Abusing Locality in Shared Web Hosting. Proceedings of the Fourth European Workshop on System Security: Article No. 2. Salzburg, Austria: Association for Computing Machinery.

[9] Urgaonkar , B., Shenoy, P., \& Roscoe, T. (2009, February). Resource overbooking and application profiling in a shared Internet hosting platform. ACM Transactions on Internet Technology (TOIT): Article No. 1 , 9(1).

[10] Bhattiprolu, S., Biederman, E. W., Hallyn, S., \& Lezcano, D. (2008, July). Virtual Servers and Checkpoint/Restart in Mainstream. ACM SIGOPS Operating Systems Review - Research and developments in the Linux kernel, 42(5), 104-113.

[11] Buyya, R., \& Bubendorfer, K. (2009). Market-Oriented Grid and Utility Computing. Wiley Publishing.

[12] Skillsoft. (2013). Cloud Computing Basics. United States of America. Retrieved August 18, 2013.

[13] Ogu, E. C., Omotunde, A. A., Mensah, Y., \& Ogbonna, A. C. (2014). Virtualization and cloud computing: The pathway to business performance enhancement, sustainability and productivity. International Journal of Business and Economics Research, 170-177.
[14] Mell, P., \& Grance, T. (September 2011). The NIST Definition of Cloud Computing. Computer Security Division, Information Technology Laboratory, National Institute of Standards and Technology, United States Department of Commerce. Gaithersburg, MD 20899-8930: National Institute of Standards and Technology. Retrieved January 28, 2014, from http://csrc.nist.gov/publications/nistpubs/800-145/SP800-145.pdf.

[15] Gartner AADI Summit. (2009). Cloud Computing as Gartner Sees it. Gartner's Application Architecture, Development \& Integration Summit.

[16] Strømmen-Bakhtiar, A., \& Razavi, A. R. (2011). Cloud Computing Business Models. Springer Computer Communications and Networks, 43-60.

[17] Ryan, S., \& Jiangchuan, L. (2012). Understanding the Impact of Denial of Service Attacks on Virtual Machines. Journal of the IEEE.

[18] Tupakula, U., \& Varadharajan, V. (2011). TVDSEC: Trusted Virtual Domain Security. Institute of Electrical and Electronic Engineers (IEEE), 57-63.

[19] Pearce, M., Zeadally, S., \& Hunt, R. (2013, February). Virtualization: Issues, Security Threats, and Solutions. Association for Computing Machinery (ACM) Computing Surveys, Article 17: 1-39.

[20] Gurav, U., \& Shaikh, R. (2010). Virtualization - A key feature of cloud computing. Proceedings of the International Conference and Workshop on Emerging Trends in Technology (ICWET 2010) (pp. 227-229). Mumbai, Maharashtra, India.: Association for Computing Machinery.

[21] Sangha, H. (2011, March 9). What is CloudBurst. Retrieved February 2, 2014, from CLOUDCREO: Virtual Solutions, Real Benefits: http://blog.cloudcreo.com/?p=1056.

[22] CDW Corporation. (2010, January 11). CDW Server Virtualization Life Cycle Report (Medium and Large Businesses). Retrieved from CDW Newsroom: http://webobjects.cdw.com/webobjects/media/pdf/Newsroom/CD W-Server-Virtualization-Life-Cycle-Report.pdf.

[23] Nagaraju, K., \& Sridaran, R. (2012, September). A Survey on Security Threats for Cloud Computing. International Journal of Engineering Research \& Technology (IJERT), Volume 1(Issue 7), $1-10$.

[24] Morrissey, M. (2014, January 10). The Future of Cloud Computing - Perspecsys. Retrieved from Cloud Data Security, Secure Cloud Data Encryption | Perspecsys: $\mathrm{http}: / /$ perspecsys.com/future-cloud-computing/.

[25] Jones, E. (2013). 2013 Future of Cloud Computing Survey Reveals Business Driving Cloud Adoption in Everything as a Service Era; IT Investing Heavily to Catch up and Support Consumers Graduating from Bring Your Own Device (BYOD) to Bring Your Own Cloud (BYOC). Palo Alto, California.: North Bridge Venture Partners. Retrieved May 28, 2014, from http://www.northbridge.com/2013-future-cloud-computingsurvey-reveals-business-driving-cloud-adoption-everythingservice-era-it.

[26] Chowdhury, K. N., \& Boutaba, R. (2009, July). Network virtualization: state of the art and research challenges. IEEE Communications Magazine, 47(7), 20-26.

[27] Soundararajan, V., \& Anderson, J. M. (2010). The impact of management operations on the virtualized datacenter. Proceedings of the 37th annual international symposium on Computer architecture (pp. 326-337`). New York, NY, USA: ACM.

[28] Miller, K., \& Pegah, M. (2007). Virtualization: virtually at the desktop. Proceedings of the 35th annual ACM SIGUCCS fall conference (pp. 255-260). New York, NY, USA: ACM. 